\title{
The Role of the Global Marketer in Market Segmentation, Product Design Decisions and Global Brands Success
}

\author{
Dr. Remy Nyukorong \\ Management Partners (GH), Wa, UWR, Ghana.
}

\begin{abstract}
This conceptual paper discusses the role of the global marketer in the segmentation process, positioning, product design decisions and the promotion of global brand success. The first part of the paper looks at the importance of creativity in the segmentation process. We emphasized that the segmentation process may look simple and straightforward, but in reality it demands a lot of experience and creativity. The second part examines the concept of global positioning as a critical success factor of a brand. We noted that a down-toearth positioning strategy can facilitate the components of the marketing plan to be reliable and supportive. In the third part, we identified and discussed product design criteria. Finally, the fourth part focused on brands that have the potential to develop cohesive and enduring relationship with customers across multiple nations and cultures. Thus, through literature search, we identified a list of ten best global brands in today's marketplace, followed by a brief discussion on the reasons of their brand power. To succeed and remain competitive, companies must be more creative, customer-centric and comprehensive.
\end{abstract}

Keywords: global brand success, creativity, market segmentation, global positioning, product design decisions

\section{INTRODUCTION}

A strong brand is not the same as a business or a trademark. A brand, whether local or global, receives its economic value from building a solid relationship with both customers and consumers (Balmer, 2013; Evan, Bridson, \& Rentschler, 2012; Urde, 1999; Urde, Baumgarth, \& Merrilees, 2013). The depth of that relationship is shaped and influenced by ideas and connections in the minds of consumers. As a result, marketers must make use of every accessible point of contact between a product and an end user so as to add lustre to germane, distinguishing, and motivating assessments with reference to their brands. Winning and profitable global brands are robust brands that go beyond their origins and build lasting relationships with customers throughout different nations and cultures. Looking at it from this perspective, several brands are global, but awfully few are internationally or worldwide successful (Nigel, 2008).

The first part of this paper examines the role played by creativity in the segmentation process. The paper observes that the segmentation process may look straightforward and simple, however in reality, it demands a bit of experience and creativity. The second part examines the concept of global positioning as a critical success factor of a brand. Therefore, this paper argues that a comprehensible positioning strategy ensures that the components of the marketing plan are reliable and supportive. Product design criteria are identified and discussed in the third part of the paper. Finally, the fourth part discusses best global brands and the reasons why they outperform other brands in the global marketplace.

\section{The Role of Creativity in the Segmentation Process}

One of the basic philosophies of marketing is the notion of market segmentation. Thus, it has now and then, been talked about as one of the possibly most creative topics of international marketing. Market segmentation is "the process of splitting customers, or potential customers, in a market into different groups, or segments, within which customers share a similar level of interest in the same, or comparable, set of needs satisfied by a distinct marketing proposition" (McDonald \& Dunbar, 2004, p.37). Kotler (1984) has singled out four conditions that a marketer can employ in assessing the suitability of potential market segments. They are accessibility, measurability, substantiality and actionability. Immediately a segment has been found which meets these conditions, it is feasible to develop a service or product which satisfies the unmet needs of the particular segment. 


\section{Dr. Remy Nyukorong}

For business organizations to completely attain the possibilities offered to them in their various markets, segmentation schemes have to concentrate on customers and their needs. Segmentation concepts based on geographical groups display barely any resemblance to real international markets. The concept of segmentation is a creative and repetitive method and its rationale is to meet the needs and preferences of customers more intimately and, by so doing, provide sustainable competitive advantage for the firm. It is characterized mainly by the consumers' needs, not the firm's, and it should at regular intervals be revisited (Goyat, 2011; Yankelovich and Meer, 2006).

It has been established that firms put restrictions to their segmentation application to a number of customers, geographies, and at best to the kinds of products bought by the customers. When done in this manner segmentation can be best described as a kind of classification methodology (Beane and Ennis, 1987; Yankelovich and Meer, 2006). In this view, the categorization is for information purposes instead of categorizing a particular clientele group to trigger existing and future profitability. Consequently, the segmentation process is to a greater extent a creative task rather than what strategic and marketing directors in their everyday pursuit make it bear a resemblance to (Kotler, Armstrong, Saunders \& Wong, 2002).

Segmentation is the commencing point of customer orientation in any business set up. It provides an indication on what is needed for creating a dedicated customer source. Furthermore, it brings about a relationship between customer allegiance and the proportion of the total sales of a product secured by one particular company or brand as well as business performance and profitability issues. In addition, segmentation needs to be centred on the strategic orientation, vision, and resource allocation among products and markets (Wind, 1978). For instance, a firm practising cost leadership policy has the obligation to segment customers according to characteristics treasured by consumers which makes it possible for the firm to operate in the markets in the most cost efficient way; and the general product conditions that can be provided by taking advantage of the critical elements such as distribution channels (Goyat, 2011; Lamp, 2003; Wedel \& Kamakura, 2000).

By means of creativity, a company will most likely be able to identify the needs, personal characteristics, future directions and identification of what kind of general relationship is needed by customers in the different segments that the company expects to customize its services or products (Freytag and Clarke, 2001; Sun, 2009). Through creative exploration, segmentation should be able to make out groups that are important to the firm's financial well-being. For example, companies can grade customers according to profitability so that they can assign the correct amount of attention to them. In addition, creativity can be accomplished by means of the experience obtained in the entire process of managing the customers. Thus, the company is required to establish and agree on the offerings that will appropriately correspond with the segments as well as the weight and significance of all the offerings to the customer. In this way, it will assist the company to identify the particular service or product pertaining to the strategy of the company and as a consequence accomplish the objectives of the company (McDonald et al., 2004).

The process of segmentation is as relevant to $\mathrm{B} 2 \mathrm{~B}$ markets just as it is to $\mathrm{B} 2 \mathrm{C}$ markets. The two types of markets are made up of customers searching for the offerings that satisfy in the most exceptional way their needs at a given price they think is giving them better value for money. Thus the process of segmentation is intended to unearth precisely what these desires are and, consequently, what kind of value proposition every segment is seeking. The practice of segmentation also assists in finding new marketing, product and service opportunities. The significance of segmentation to any enterprise must not to be taken too lightly since market segmentation remains the fundamental element for successful marketing planning and need to mirror a market/customer focus instead of a service or product focus (McDonald et al., 2004). Good market segmentation, according to Yankelovich and Meer (2006), singles out the cluster of people most attractive to pursue, namely, people who are underserved, those that are dissatisfied, and potential unique and first-time purchasers.

Creative and implementable market segmentation solutions usually provide the business firm a tactical advantage over companies it is competing with. Thus, if a business firm can focus on its markets by means of a creative novel idea on how that marketplace is organized and run as well as discover the desires, needs and wishes of the various segments within the market, then it has the chance to take action to increase profitability, repeatedly at the cost of the business rivalry. It is therefore not surprising that companies usually go into a local market through market segmentation, bringing to light a niche that is under-served, and subsequently focusing their selling and economic 
assets into that particular niche. When created and frequently taking control in that position, other market raiders exercise their assertive posture in the niche as a source of action to develop into and break through other market segments (SDR Consulting, 2004). Creative segmentation needs not only specialized and scientific know-how but also knowledge of the customer, business intelligence, a powerful sense of managerial and organizational dynamics, wisdom, and lastly some amount of guts and resilience.

\section{Global Positioning as a Fundamental Asset of a Brand}

Marketers all over the world throw thousands of messages every day at the average consumer. With a lot of noise generated by this act, the danger of a company's advertising efforts passing without being seen are extremely high. The only possible way to manage this risk is through positioning: designing a central position around the company's most essential competitive differentiation and placing that differentiation securely in the minds of potential customers (Keegan and Green, 2013; Nigel, 2008).

Marketers have more and more utilised positioning strategies to attract either local or global consumer cultures (Stanford, Singh, \& Magnusson, 2012). There are various meanings of positioning as there are many marketing managers. Thus, positioning could mean segmentation decision, image, or selecting which particular product attributes to highlight (Aaker \& Shansby, 1982). A product or a company has numerous families of relations which come together to create a complete idea. The positioning decision usually indicates those relations which are well coordinated and give emphasis on as against those linkages that are to be thrown out or assign less importance to. Also, the positioning decision is frequently considered the critical evaluation tool for any business organization or brand since a given position can be fundamental to the discernment of customers and their preferences (Aaker and Shansby, 1982). Therefore, it is often a great necessity to make use of a positioning policy as a motivating factor for the enhancement of the marketing plan. A transparent and comprehensible positioning strategy can certify that the various components of the marketing plan are coherent and helpful.

A thorough grasp of what positioning involves is a vital prerequisite for any person engaged in the area of brand development. Notable examples are branding consultancies as well as advertising associations (Dinnie, 2008). What usually does not go down well with marketing promotions is the fact that some marketers are resolute on branding when the most important and first thing is to focus on positioning. Brand value alone is not sustainable if it fails to go along side with appropriate positioning. Moreover, it is in the position itself that a brand's essential distinction and implicit value is based on. A brand promotion devoid of a positioning scheme is like advertising on the spur of the moment (Innis Maggiore Group, 2013). For instance, many firms would not go ahead to introduce products without really being knowledgeable about market intelligence. In spite of that, it is startling to see how many companies compete unquestionably with their brands, not becoming conscious of the fact that it is their market worth that eventually is put at risk.

Positioning mirrors important useful qualities and naturally searches for ways to align with leadership values. The object that makes positioning a long-term concern as a market advantage is its concentration on the most valuable economical differentiation one has to offer. For example, Dove created its competitive differentiation as the "beauty bar" in a class where all else became merely soap (Innis Maggiore Group, 2013).

Below, we outline the advantages of global positioning according to Innis Maggiore Group (2013):

- Determines the long-term strategic orientation for the company's brand based on its core realities as well as the competitive business terrain.

- Stipulates all the P's involved in marketing, namely: people, priorities, product, promotion, price, priorities, and place. It also coordinates them within the framework of a distinct, all-encompassing strategy that leads to reliability and steadfastness to all the activities that the company is involved in.

- Develops and promotes trust and fidelity among consumers as well as with customers. Increases efficiencies in cost in the area of communication for best possible ROI (return on investment).

- It provides guidance as to what to do, and what not to do or should be stopped from doing. In this way, it assists in ascertaining the things that dissuade and detract from the company's principal goal and fails to add value. 
- It is cumulative, executed successfully in the fullness of time; it develops brand equity and creates goodwill.

- It is the distinctive and characteristic centre of the marketing mix, the company's indispensable "anatomy."

- Determines a comprehensible central point for the promotion and assessment of every selling and advertising communication.

Besides the benefits of global positioning, Aaker and Shansby (1982) have identified four positioning strategies which the global marketer can make use of. They are (1) positioning by attribute (take advantage of a certain product attribute, benefit, or characteristic such as durability, reliability and economy); (2) positioning according to quality and price; (3) positioning according to use or user (shows how a product or service is put to use or relates the brand with a consumer or category of users); and (4) positioning according to competition. Beside these, there are other important positioning strategic alternatives based on a worldwide marketing philosophy such as local consumer culture positioning, foreign consumer culture positioning and global consumer culture positioning (Aaker \& Shansby, 1982, Keegan \& Green, 2013). Next, we will briefly explain them.

First, global consumer culture positioning (a.k.a. GCCP) can be described as an approach that recognizes the brand as a symbol of a special universal culture or sector (Stanford et al., 2012). This strategy has demonstrated to be a useful tool for communicating with young people, multinational elites and several unique groups worldwide. High technology and high-touch products are categories that fall under GCCP strategy (Keegan and Green, 2005). Consumers may experience an emotional or sacred association with high-touch products; the functioning of this is assessed in subjective, aesthetic basis instead of objective, technical basis (de Mooij, 2010; 2004). Thus a brand's global consumer culture positioning can be strengthened by a well thought-out choice of the thematic, spoken, or visual elements that are integrated into advertising and other means of communications.

Second, the term "Foreign consumer culture positioning" (FCCP), relates the brand's users, utilization events, or production sources with a foreign nation or culture (Stanford et al., 2012). At times, FCCP strategy is applied in automobile advertising. Other times, brand names evoke an FCCP even supposing a product has a local source.

Thirdly, global marketers can make use of local consumer culture positioning (LCCP), a policy that connects the brand with home cultural values, mirrors the home cultural values and customs, depicts the brand as a local consumption item by the local people (de Mooij, 2004; Stanford et al., 2012). A research study about television advertising, which was carried out in seven different countries established that LCCP prevailed, chiefly in classified adverts for food, private nondurables and individual domestic nondurables (Keegan and Green, 2005).

\section{Criteria for Making Product Design Decisions}

Variations in design are mainly determined and influenced by whether or not they would generate larger sales and revenues than associated costs (Cost-benefit analysis). Variations in design are also dependent on cultural demands. The more culture-oriented a product is the more modification is required. Many products or commodities come somewhere in between the range of adaptation and standardisation extremes. Product adaptation is described as the extent to which the material features or elements of a product including its packaging vary from country to country (Calantone, Cavusgil, Schmidt \& Shin, 2004). Standardization, on the other hand, refers to the principle of selling essentially the same product in all markets.

There are several benefits of this marketing strategy such as reduced prices as a result of economies of scale and experience in the designing process, production and distribution of the same products in different places (Calantone et al., 2004). The common market in Europe, for instance, suggests a universal coordinated standard for various products and services. This gives options to business firms to design products relevant to all countries in Europe, bearing in mind, the outstanding cultural differences that prevail within Europe as a regional block. Even so, safety requirements of products in Europe are, in spite of everything, determined on the basis of each individual country (Keegan \& Green, 2013). Thus, providing similar products can be unattractive owing to variations in the regulatory environment, delivery channels, the degree of market and technological advancements, competitive situation as well as cultural dynamics in the individual countries. In view of the fact that customers in various nations have diverse and unique needs, the standardization of products may not 
be a suitable strategy to apply. Despite the fact that adapting products for diverse markets augments costs, the custom-made products may better suit the needs and preferences of customers or consumers in different countries. This will naturally lead to increased consumption, more sales, increased revenue and higher profit margins.

Some decisive factors or principles which the global marketer should consider when making product design decisions are:

Local versus standard products and brands: The fundamental nature of marketing in discovering needs and satisfying them. Maslow's hierarchy of needs gives a constructive framework for comprehending how and why home-products and brands can be broadened further than national country boundaries. Maslow theorized that people's desires can be organized into a pecking order of five needs. As a person satisfies needs at each level, he or she steps forward to higher levels (Maslow, 1970). Also products can accomplish diverse needs in various countries. One of the hard realities of life in international marketing is that good insight about and attitude towards certain countries usually extend to products and brands that have their origin in those nations. This kind of perception leads to the country-of-origin effect; they become part and parcel of a brand's image and add to brand equity (Keegan and Green, 2005, p.341). Thus, perceptions and attitudes concerning the source of a product can either be negative or positive. For instance, German is usually associated with producing high quality automotive products. Thus, country-of-fabrication, country-of-make up, and country origins for parts can all constitute critical considerations (Keegan and Green, 2005).

Packaging: this is an essential consideration for goods and products that are transported to markets located worldwide. Eco-packaging is a major concern today; as a consequence package designs need to tackle environmental concerns such as recycling and biodiversity. Germany is a typical example where product packaging must measure up to "Green Dot" (Grüner Punkt) convention. Parallel Green Dot schemes have been initiated and implemented in most European States. Furthermore, packaging serves vital communication purposes. In our day, there are many business experts who concur that packaging must connect the senses, make emotional engagements, and increase a consumer's brand experience (Keegan and Green, 2013).

Labelling: One characteristic of the current global market environment is the profusion of multilanguage labelling that become visible on scores of products. In the present self-service trade environments, labels on products may be designed to create a centre of attention, to buttress a product's positioning, and to aid influence consumers to purchase. Also, labels can offer customers as well as consumers with different kinds of useful information (Keegan and Green, 2013).

Aesthetics: Global marketers must appreciate and understand the significance of visual aesthetics alive in the colour or appearance of product, trade mark, or package. Similarly, aesthetic designs such as the extent of intricacy and density seen on a label are understood differently in several regions of the globe (Keegan and Green, 2013).

Product warranties: A warranty can be an essential component of a product's value proposition (Keegan and Green, 2013). An express warranty which is a written certification that gives surety to the consumer for receiving what he or she has paid for or that gives remedy should a product's performance fails to meet the consumer's expectations. In global marketing, warranty is perceived as a competitive devise to place a firm in a favourable position. Therefore, it is an important factor to take into consideration when design a product.

Extend, adapt, and create: To take advantage of prospects outside the home country, managers of business organizations need to formulate and put into practice suitable marketing plans. Governed by firm objectives and market requirements, an individual plan may be made up of extension and adaptation strategies, or else a blending of the two strategies. A business organization that has formulated a profitable home product or brand can apply an extension approach that requires putting out a product practically unmodified in markets outside the native land. A second alternative to consider is an adaptation approach; this requires altering the design, task, or packaging component in response to the desires, wants and circumstances in individual domestic markets. These product approaches can be applied in combination with adaptation or extension communication policies. A third and final strategic alternative is product invention, which involves coming up with new products "from the ground up" perspective with the global market at the back of your mind (Keegan and Green, 2005, p.346). 


\section{Dr. Remy Nyukorong}

The choice to produce, broaden, or modify is subject to various factors bordering on firm-specific objectives in addition to the socio-cultural, monetary, financial and political settings (Keegan and Green, 2013). Regardless of the fact that tastes, needs and preferences are becoming similar everywhere in the world, substantial differences are still present in the context of what consumers need and long to get. Thus marketing managers who do not take into account such disparities and go ahead to embrace and implement extension strategies for the benefit of economies of scale or convenience do so at their own risk. The regulatory environment in the individual countries often brings about binding product design localization. This situation may be observed most visibly in Europe, where drive for the establishment of the European market became the aspiration to dislocate rigid, myopic and legal obstacles that put a stop to the sales of standardized products throughout all the European countries.

\section{Some Global Brands and Reasons for Their Success in the Global MARKETING}

A brand is a dense package of images and experiences in the psyche of the consumer. In many nations throughout the world, local brands keenly vie with both transnational and worldwide brands. A home product is accessible in a particular country while a global product meets the desires and needs of consumers in all markets. In similar manner, a global brand possesses identical name and identical image and it is positioned in a larger segment of the global market. Nigel Hollis (2008) defines a global brand as "one that has transcended its cultural origins to develop strong relationships with consumers across different countries and cultures" (Hollis, 2008, p.25-26). Global brands are perceived to be influential institutions, possessing the ability to achieve many positive things, but at the same time can be the root of significant destruction (Holt, Quelch, \& Taylor, 2004). Furthermore, global brands have become a language of effective communication for all consumers worldwide.

Consumers throughout the business world connect global brands with three main features (quality signal, global myth and social responsibility) and consumers assess global brands on these three qualities as they make their buying decisions (Holt et al., 2004). Scores of global companies influence positive brand images and superior brand equity by utilizing co-branding, combination branding and brand extension approaches (Keegan and Green, 2013). Also, firms can build robust brands in all markets worldwide by means of global brand leadership.

There are several global brands in the world today. Some of the world's best global brands include: Coca- cola, IBM, Ford, Google, Mercedes- Benz, Pepsi, HP, Blackberry, Nike, Microsoft, Amazon, Gillette, Santander, Kellogg, Apple, McDonalds, and so forth. However, there are new cohorts of global brands surfacing in the marketplace. With brands more and more going global, marketers are required to modify and sanitise their strategies to be certain that their brands are useful and yield good returns (Cooper, 2010).

There are five recommended strategies which marketers can adopt and implement in their marketing activities in order to accomplish success. They are (1) building a robust, enduring and reliable brand culture; (2) practicing borderless marketing; (3) setting up a well-coordinated marketing team; (4) implementing a "glocal" structure; and (5) making consumers co-creators (Cooper, 2010). The under listed successful global brands may have utilised some of these strategies in their marketing undertakings.

Table1. The top ten 2016 Best Global Brands

\begin{tabular}{|l|l|l|l|l|c|}
\hline 2016 Rank & Brand & Sector & Country & Brand value (US \$m) & Value change value (\%) \\
\hline 1 & Apple & Technology & U.S. & 178,119 & 5 \\
\hline 2 & Google & Technology & U.S. & 133,252 & 11 \\
\hline 3 & Coca-Cola & Soft Drinks & U.S. & 73,102 & -7 \\
\hline 4 & Microsoft & Technology & U.S. & 72,795 & 8 \\
\hline 5 & Toyota & Automotive & U.S. & 53,580 & 9 \\
\hline 6 & IBM & Technology & U.S. & 52,500 & -19 \\
\hline 7 & Samsung & Technology & South Korea & 51,808 & 14 \\
\hline 8 & Amazon & Retail & U.S. & 50,338 & 33 \\
\hline 9 & $\begin{array}{l}\text { Mercedes } \\
\text { Benz }\end{array}$ & Automotive & U.S. & 43,490 & 18 \\
\hline 10 & General & Automotive & U.S. & 43,130 & 2 \\
& Electric & & & & \\
\hline
\end{tabular}

Source: Interbrand Releases 2016 Best Global Brands Report 
For four consecutive years, Apple and Google obtained the top positions with technology and automotive brands dominating the ranking. Apple's brand value grew by 5 percent to USD $\$ 178,119 \mathrm{~m}$, while Google's brand value rose 11 percent to USD $\$ 133,252 \mathrm{~m}$. Coca-Cola, Microsoft, Toyota, IBM, Samsung, Amazon, Mercedes-Benz and GE added to the top ten. The ranking was evaluated on three key factors that contributed to brand's aggregate value: (a) the role the brand played in motivating customer choice, (b) the power the brand has to claim premium price or obtain earnings for the company, and (c) the financial performance of the branded goods and services (Interbrand Report, 2016). Thus, growth is accomplished when a firm has a well-defined strategy and provides unique and excellent customer experiences.

Before we next discuss some of the factors that made these best global brands to distinguish themselves in the marketplace, it is appropriate to emphasize two points. First, the capability to be both local and worldwide is critically important to thrive in international marketing ventures. Second, brands that fail to embrace a "boundary-less" marketing policy risk being pushed away from the centre of competition.

\section{REASONS FOR THE SUCCESS STORY OF THE BEST GLOBAL BRANDS}

Among all the top brands catalogued in its Best Global Brands ranking for the past five years, Interbrand considers collaborative leadership approach as a general theme for success. The chief executive officer of Interbrand, Jez Frampton, throws more light on this when he categorically declares:

"In today's global and social media-obsessed marketplace, brand leaders recognize the need to be highly collaborative. The top 100 most valuable global brands are unlocking their value by participating, listening, learning, and sharing - and not just with leaders from within their organization, but with consumers too. Brands that learn to think differently about the role they play in consumers' lives - and how to fulfil that role - have an opportunity to change the world in ways they never imagined" (Interbrand, 2013).

To attain more success and to create global brands with enduring and lifelong value, corporate leaders need to be paying special attention to the needs, tastes and preferences of customers. This paper further emphasizes that unless a product or service can be made, allocated, and sold economically, it has very weak prospects of creating and fostering an enduring relationship with a large number of consumers all over the world. Nonetheless, a robust scalable corporate model does not necessarily produce a solid brand. It is the stage and foundation on which solid brands are developed. All the best-ranked brands make use of a diversity of business prototypes, which have all been adapted to fulfil the needs of the home customers, the indigenous trade infrastructure as well as the enterprise financial system. Devoid of these shifting platforms, the brands would be unable to serve on consumers' expectations, the primary and necessary prerequisite of any brand (Nigel, 2008).

The ninth-ranked brand in 2015, McDonald's, is a typical example of how a corporate model succeeded in creating a whole service group. From the beginning, the stress of the food company has always been on retailing massive volumes of a controlled quantity of products as cheaply but costeffectively as possible. This approach afforded McDonald's a relaxed opportunity to make use of economies of scale and regulate quality successfully. In establishments that deal with convenience foods, consumers do most of the work customarily performed by workers of more typical restaurants. The processes of standardization make it possible for employees to perform with fairly little guidance or payment. Nevertheless, this should not be interpreted to mean that McDonald's has not been flexible in its operations. It has frequently adapted its set of choices in various locations in the world while still providing food of reliable quality at reduced prices.

Furthermore, no matter how creative and entertaining branding campaigns are designed, without leveraging the emotional features of the products, a company's marketing strategy alone may fail to resonate with people. The old adage, "feelings are facts", hold true in the minds of consumers (Scott, 2015). Therefore, whether brands are interacting well with a potential customer for the first instance or satisfying for a long-time consumer, it is important to promote positive emotional links from the beginning. By fostering an emotional connection with customers, Apple has developed a loyal following, and there is no doubt that brand loyalty has played a big role in Apple's global success (Chapman, 2016). When David Di Franco was asked about what the Apple brand meant to him, this was his response: 
"Ever since switching to the Mac in 2004, I knew there was something about Apple that really connected with me on a personal level. From the consistency in their product designs to the passion behind what they stand for, Apple has quickly become one of my favorite brands of all time. And honestly, I don't see that changing anytime soon. I'm now an Apple fan for life" (Chapman, 2016).

The key to brand loyalty is based on transparent and trustworthy communications with customers. Thus, it is critical that companies learn how to communicate what their organizations believe in to relate to the target market. Apple communicates effectively with its teaming customers through its software, hardware as well as retail stores to offer one consistent ecosystem or narrative (Adrianne, 2016). Apple's worldwide branding success is largely attributed to its inspiring mission statement, which states: "Apple is committed to bringing the best personal computing experience to students, educators, creative professionals and consumers around the world through its innovative hardware, software and Internet offerings" (Chapman, 2016). This statement resonates across all its business units.

Innovation is another essential factor to brand success. However, this does not mean that one has to be the first to design a new product or service in order to be successful. Tellis and Golder (2006) establish that companies such as Gillette, HP and Apple grew to be profitable by taking advantage of the shortcomings of the first mover's product or corporate model. These researchers disclosed that first movers fail in sixty-four percent of all industries surveyed (p.42) and therefore arrived at the conclusion that:

"The real causes of enduring market leadership are vision and will. Enduring market leaders have a revolutionary and inspiring vision of the mass market, and they exhibit an indomitable will to realize that vision. They persist under adversity, innovate relentlessly, commit financial resources and leverage assets to realize their vision" (Tellis and Golder, 2006, p.41).

Thus, innovation remains the linchpin of Nokia's success today. However, reliance on innovation alone can be a double-edge sword (Nigel, 2008). A firm that relies on innovation must be abreast with the most modern developments and maintain the innovation channel systematically. The Toyota assembly control structure is renowned. The Global Business Services report of IBM (2006) identifies innovation as well as an adaptable business model to be strategic drivers for the automotive company's profit augmentation. The report features Toyota's talent to foresee and respond rapidly to shifting consumer needs due to the way it has been able to adjust its manufacturing systems, but at the same time, keeping product safety and reliability (Ban, Henderson, Koppinger \& Stanley, 2006).

According to Nigel (2008), five additional related and overlying factors are required to keep a company successful and competitive: "a great brand experience, clear and consistent positioning, a sense of dynamism, a sense of authenticity and a strong corporate culture" (p.56). A typical example of a global brand that has kept to an outstanding and constant positioning in the business world is Procter \& Gamble's Pantene Pro-V. The heart and focal point of that illustrious positioning is healthy, shining hair. This brand clearly was the first worldwide winning $P \& G$ brand to be produced outside its country of origin, the U.S. The worldwide hair-care industry has often been distinguished by hard to believe brand explosion. There are plethora of brands produced for sale in almost every country: value brands, wide-range offerings, kudos brands, as well as beauty salon brands. The swiftness of innovation has characteristically intended that the complete process of change and development of a hair-care brand is somewhat terse. Thus, Pantene Pro-V is one of the very few trade names that have managed to endure the pace and tempo of change for over ten years. The brand's equity was measured in twenty-six nations and in twenty of these countries it attained a robust linkage with consumers. Pantene Pro-V is specifically concentrated in China and Thailand area (Aaker \& Joachimsthaler, 1999; Nigel, 2008).

Milligan and Smith (2002) in the introductory chapter to their book entitled, Uncommon Practice, offer a sequence of case studies to substantiate their hypothesis that a number of business organizations perform well due to the fact that:

"their cultures are uniquely developed to meet the needs of their customers in a distinctive way. Critical to the development of that culture is a genuine belief in, and commitment to, the people in the business that has engendered a loyalty uncommon 
amongst many organizations. This loyalty translates onto a genuine passion for their customers" (Milligan \& Smith, 2002, p. ix).

Some of the companies that have made it to the top of the Best Global Brands 2016 survey possess an enduring and resilient global corporate culture.

These critical success factors discussed above, though seen as common sense and rational, they are rarely practice in the marketplace. While numerous companies may show signs of them, the first ten best global brands that we identified in table 1 above, in reality have lived and put into practice most of these critical factors. It is this comprehensive picture of the company and brand that has distinguished these "Best global" companies the champions that they are today.

\section{CONCLUSION AND FUtURE RESEARCH}

The basic challenge for global brand marketers is to make a distinction between the components of a brand which can be sold to other countries with economic benefits as well as brands that need to be adapted. As it was once said by Geoffrey Probert, a Unilever senior executive officer, the object of a global marketer is to discover the precise "balance between mindlessly global and hopelessly local" (Probert, 2003). Firms competing at the global level must strive to achieve that optimal balance so as to promote and sustain profitable growth for their products.

Furthermore, global marketers need to consider the efficiency and effectiveness of creating an international marketing promotion alongside the need to be responsive to national differences and culture. To go very far in the localization process will lead to the loss of efficiencies; and indeed, it will be better rather for a firm to introduce an entirely new brand in every country. On the other hand, to fail to localize the offer satisfactorily will lead to significant dissipation of business investments as well as the opportunity cost of lost sales. Figuring out the optimal balance between local and global is not always a simple and clear-cut task. A careful and creative understanding of local requirements, desires, and wishes is crucially needed to effectively manage a product or brand at the worldwide business stage. Further conceptual and empirical studies are required to illuminate the role of brand orientation in global marketing. Wong and Merrilees (2007) propose investigating the impacts of different global branding matters on international firm performance. Specific areas could include the external market settings, managerial personal attributes, interrelationships among firms' branding and marketing and branding strategies, as well as firm performance from the global marketing perspective. Thus, further empirical findings in the above themes in the global framework could offer a more comprehensive view of the role of brand orientation in the global marketing setting.

\section{REFERENCES}

Aaker, D.A. \& Joachimsthaler, E. (1999). The lure of global branding. Harvard Business Review, November-December, 137-144.

Aaker, D.A. \& Shansby, J.G. (1982). Positioning your product. Business Horizons, 25, 56-62.

Adrianne, P. (2016, October). The Power of cohesive branding. Advertising Age.

Retrieved 10 April 2017 from http://adage.com/article/cmo-strategy/power-cohesive-branding-applewins/306325/

Akaka, M.A. \& Alden, D.L. (2010). Global brand positioning and perceptions: International advertising and global consumer culture. International Journal of Advertising, 29(1), 37-56.

Alden, D.L., Steenkamp, J.B. \& Batra, R. (1999). Brand positioning through advertising in Asia, North America, and Europe: The role of global consumer culture. Journal of Marketing, 63(1), 75-87.

Balmer, J. (2013) Corporate brand orientation: What is it? What of it? Journal of Brand Management, 20(9), 723-741.

Ban, L., Henderson, A., Koppinger, P. \& Stanley, B. (2006). Changing Lanes for Success: Flexible Automotive Business Models in Times of Accelerated Change. IBM Global Business Services: Somers, New York.

Beane, T.P., \& Ennis, D.M. (1987). Market segmentation: A review. European Journal of Marketing, 21(5), 20-42. Doi: 10.1108/EUM0000000004695. 
Calantone, R.J., Cavusgil, S.T., Schmidt, J.B., \& Shin, G. (2004). Internationalization and the dynamics of product adaptation - an empirical investigation. The Journal of Product Innovation and Management, 21, 185-198.

Chapman, N. (2016, June). The World's Most Valuable Brand: Apple's Secret to Success.

Retrieved 09 April 2017 from https://blog.bynder.com/en/the-worlds-most-valuable-brand-applessecret-to-success

Cooper L. (2010, July). Five strategies for a successful global brand. Marketing Week, 13-16.

Evans, J., Bridson, K., \& Rentschler, R. (2012). Drivers, impediments and manifestations of brand orientation: An international museum study. European Journal of Marketing, 46(11/12), 14571475 .

De Mooij, M. (2010). Global marketing and advertising: Understanding cultural paradoxes (3rd ed.). Thousand Oaks, CA: Sage.

De Mooij, M. (2004). Consumer behavior and culture: Consequences for global marketing and advertising. Thousand Oaks, CA: Sage.

Dinnie, K. (2008). National branding: Concepts, Issues, Practice. Oxford: Elsevier.

Follmer, M. (2013, September). Discovery lands on list of world's most valuable brands. Retrieved November 20, 2013, from http://www.brief-promaxbda.org

Freytag, P.V.,\& Clarke, A.H. (2001). Business to business market segmentation. Industrial Marketing Management, 30(6), 473-486.

Goyat, S. (2011). The basis of market segmentation: A critical review of literature. European Journal of Business and Management, 3(9), 45-54. Retrieved November 19, 2013, from http://www. iiste.org /Journals/index.php/EJBM/article/download/647/540

Holt, D .B. (2004). How brands become icons: The principles of cultural branding. Harvard MA: Harvard University Press.

Holt, D.B, Quelch, J.A. \& Taylor, E.L. (2004). How global brands compete. Harvard Business Review. 68-75.

Interbrand (2013). Best global brands: Top 100 list. Retrieved November 11, 2013, from http://www. Interbrand.com/en/best-global-brands/2013/top-100-list-view.aspx

Interbrand Report (2016). Interbrand Best Global Brands 2016. Retrieved 11 April, 2017 from http:// interbrand.com/best-brands/best-global-brands/2016/

Innis Maggiore Group (2013). The point of positioning. Retrieved November 15, 2013, from http:// www.innismaggiore.com/Difference/Positioning.aspx.

Keegan, W.J., \& Green, M.C. (2013). Global marketing (7th ed.). New York, NY: Pearson Prentice Hall.

Keegan, W.J., \& Green, M.C. (2005). Global marketing (4th ed.). United States: Pearson Prentice Hall.

Kotler, P. (1984). Marketing management: Analysis, planning and control. New Jersey: Prentice Hall.

Kotler, P \& Armstrong, M. (2006). Principles of Marketing (12th edn.). New Jersey, USA: PrenticeHall, Eaglewood Cliffs.

Kotler, P., Armstrong, G., Saunders, J. \& Wong, V. (2002). Principles of marketing ( $3^{\text {rd }}$ edn.). London: Prentice-Hall.

Lamp, C.W. (2003). Marketing. Beijing: Peking University Press.

Maslow, A. H. (1970). Motivation and personality (2nd edn.). New York: Harper \& Row.

McDonald, M. \& Dunbar, I. (2004). Market segmentation: How to do it, how to profit from it. Jordan Hill, Oxford: Elsevier Butterworth-Heinemann Linacre House

Milligan, A. \& Smith, S. (2002). Uncommon practice: People who deliver a great brand experience. Great Britain: Pearson Education.

Morris, R. (2009). The fundamentals of product design. USA: AVA Publishing.

Probert, G. (2003, April 8). Meeting client needs now and in the future. Presentation, Millward Brown CEO Conference, Arion Hotel, Astir Palace Resort, Vouliagmeni, Greece. 
Stanford, A. W., Singh, N., \& Magnusson, P. (2012). Responsiveness to global and local consumer culture positioning: A personality and collective identity perspective. Journal of International Marketing, 20(1), 58-73.

Sun, S. (2009). An analysis on the conditions and methods of market segmentation. International Journal of Business and Management, 4(2), 63-70.

SDR Consulting (2004). Lessons learned in market segmentation: A perspective on the design and implementation of market segmentation strategies. Retrieved November 13, 2013, from http://www.sdr-consulting.com/article18pdf

Tellis, G. \& Golder, P. (2006). Will and Vision: How latecomers grow to dominate markets. Los Angeles: Figueroa Press.

Urde, M. (1999). Brand orientation: a mindset for building brands into strategic resources. Journal of Marketing Management, 15(1-3), 117-133.

Urde, M., Baumgarth, C., \& Merrilees, B. (2013). Brand orientation and market orientationFrom alternatives to synergy. Journal of Business Research, 66(1), 13-20.

Wedel, M., \& Kamakura, W.A. (2000). Market segmentation: Conceptual and methodological foundations (2nd edn.). Boston, MA: Kluwer Academic Publishers.

Wind, Y. (1978). Issues and advances in segmentation research. Journal of Marketing Research, 15(3), 317-337. URL:http://www.jstor.org/stable/3150580.

Wong, H.Y. \& Merrilees, B. (2007). Multiple roles for branding in international marketing. International Marketing Review, 24(4), 384-408.

Yankelovich, D. \& Meer, D. (2006, February). Rediscovering market segmentation. Harvard Business Review, 122-131.

\section{AUTHOR's BIOGRAPHY}

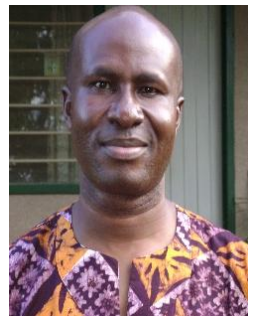

Remy Nyukorong, received his Doctor of Business Administration from the Swiss Management Center University in Switzerland. He was the Head of the Accountancy, Banking and Finance Department of Wa Polytechnic, Ghana. He is currently the General Treasurer of Stichting Kongregatie F.I.C., Maastricht, The Netherlands. Remy is also a research fellow (Honorary) of Maastricht School of Management, and co-founder of Management Partners (GH) and pro-bono advisor of Duong Information and Development Empowerment (DIDE), a Ghanaian nongovernmental organisation promoting entrepreneurship, microfinance and healthcare services in rural communities. His research interests include Entrepreneurship and Innovation, Finance and Investment Management, Organisational Behaviour, Strategic Leadership and Governance as well as Service and Consumer Marketing. 